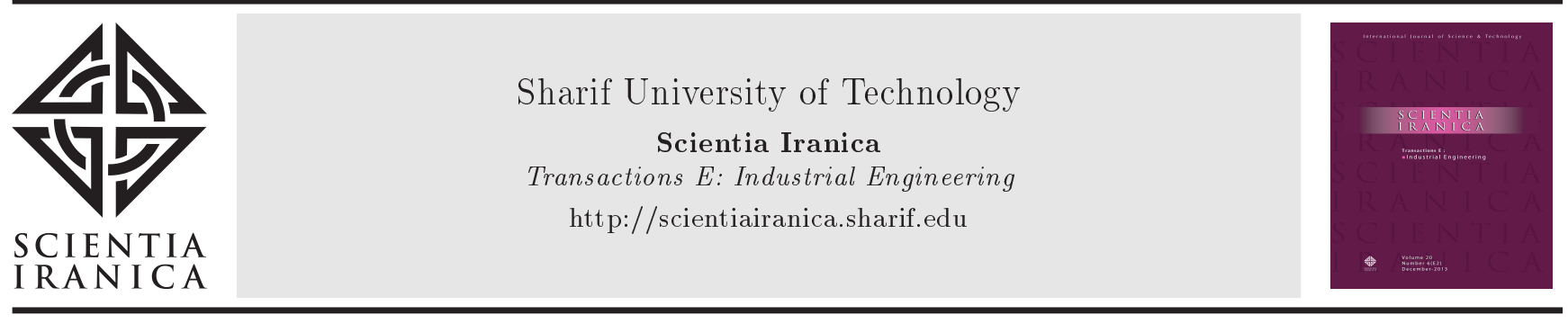

\title{
An integrated lot-sizing model for imperfect production with multiple disposals of defective items
}

\author{
Y.-L. Cheng ${ }^{\mathrm{a}, *}$, W.-T. Wang ${ }^{\mathrm{a}}$, C.-C. Wei ${ }^{\mathrm{a}}$, and K.-L. Lee ${ }^{\mathrm{b}}$ \\ a. Department of Marketing and Distribution Management, Chien Hsin University of Science and Technology, Jungli 32097, \\ Taiwan, R.O.C. \\ b. Department of Industrial Management, Chien Hsin University of Science and Technology, Jungli 32097, Taiwan, R.O.C.
}

Received 29 February 2016; received in revised form 5 November 2016; accepted 10 December 2016

\author{
KEYWORDS \\ Inventory; \\ Integrated lot-sizing \\ model; \\ Defective items; \\ Multiple disposals.
}

\begin{abstract}
In this study, an optimal integrated vendor-buyer inventory model with defective items is proposed. Most researches on defective items assumed that an inspection process was carried out by the buyer. We consider that the vendor conducts the inspection process and disposes defective items in multiple batches. We prove that the function of annual cost is convex, and obtain closed-form expressions. A solution procedure is used to derive the optimal order quantity, the number of shipments, and the number of defective item disposals. Numerical examples are provided to illustrate our model. Setting the fraction of defective items to zero, the numerical examples indicate that the proposed model can result in the solutions to the existing models without considering defective items. Moreover, a sensitivity analysis is used to reveal the effects of cost parameters on the optimal solution. We show that when the disposal cost is relatively low, a multiple disposals strategy may perform better than a single disposal strategy.

(C) 2018 Sharif University of Technology. All rights reserved.
\end{abstract}

\section{Introduction}

The problem of vendor-buyer integration is considered as the foundational research topic in supply chain management. The objective is to minimize the total system cost or maximize the entire system profit. One of the first integrated inventory models consisting of single vendor and single buyer was proposed by Goyal [1]. Banerjee [2] modified Goyal's [1] model considering a finite production rate for the vendor who followed a lot-for-lot shipment policy. Goyal [3] relaxed the lotfor-lot policy and proposed an integer multiple of equal-

\footnotetext{
*. Corresponding author. Tel.: +886-3-4581196;

Fax: +886-3-2503032

E-mail addresses: jkcheng54@uch.edu.tw (Y.-L. Cheng); wangwt2006@gmail.com (W.-T.Wang);

d887801@uch.edu.tw (C.-C.Wei); klee@uch.edu.tw (K.-L. Lee)
}

doi: $10.24200 /$ sci.2017.4414 size vendor production quantity shipments. $\mathrm{Lu}$ [4] then generalized Goyal's [3] model by relaxing the assumption that the supplier could supply the retailer after completing a production batch. Goyal [5] developed a policy with which the shipment sizes increased by a fixed factor, which was equal to the production rate divided by the demand rate. Hill [6] proposed a generalized policy for shipment batches increasing by a geometric growth factor. Several researchers (e.g., [7$9]$ ). proposed different batching and shipping policies for the integrated inventory models.

Since then, many extensions have been made to the basic integrated production inventory models. Huang [10] investigated the effect of quality on lot sizes for a single-vendor single-buyer inventory system. Nieuwenhuyse and Vandaele [11] proved that lot splitting policies would benefit both the supplier and the buyer. Ertogral et al. [12] developed an integrated vendor-buyer model under equal-size shipment and added transportation cost to the model. 
Lin [13] proposed an integrated single-vendor singlebuyer inventory model with backorder price discount and variable lead time. Sajadieh et al. [14] discussed an integrated model where the demand was dependent on the amount of goods displayed on the shelf. Sari et al. [15] considered an integrated vendor-buyer problem where the supplier offered temporary price discounts to the buyer during a sale period. Readers are referred to Glock [16] for a comprehensive review of integrated systems. Rad et al. [17] suggested a joint economic lot sizing model of a single-vendor single-buyer supply chain for items with imperfect quality and shortages under price-sensitive demand. Lee and $\mathrm{Fu}$ [18] analyzed an integrated production and delivery quantity model in a make-to-order producer-buyer supply chain. Sarakhsi et al. [19] studied a joint economic lot-sizing problem for a single-vendor single-buyer system where the demand was dependent on selling price. Some recent works on integrated vendor-buyer models have been done by many researchers, such as Lin [20], Yi \& Sarker [21], Wee \& Widyadana [22], Ouyang et al. [23], Giri \& Sharma [24], and Chung et al. [25].

Rosenblatt and Lee [26] was one of the first models to consider imperfect production inventory models. Salameh and Jaber [27] presented a classic economic order quantity model in which the order lot contained a random proportion of imperfect quality items. Many extensions and modifications regarding quality issues have been researched recently. Wee et al. [28] and Eroglu and Ozdemir [29] extended Salameh and Jaber's [27] inventory model to consider shortages with complete backorders. Subsequently, Chang and Ho [30] revisited the inventory model of Wee et al. [28] and derived closed-form optimal solutions by applying Renewal Reward Theory. Hsu and $\mathrm{Yu}$ [31] studied a one-time-only discount policy for an economic order quantity model that considered imperfect quality items. Maddah et al. [32] presented an approach to avoid shortages during the screening period. Khan et al. [33] provided a detailed and complete review for economic order quantity models with imperfect quality items. Chang et al. [34] and Yassine et al. [35] developed an economic production quantity model for imperfect quality items. Rezaei and Davoodi [36,37] provided inventory models that considered supplier selection and imperfect quality. Moussawi-Haidar et al. [38] and Rezaei [39] investigated economic order quantity models where imperfect items were screened with sampling inspection plans. Hsu and Hsu [40] provided economic production quantity models to determine the optimal lot size and backorder quantity under imperfect productions. Taleizadeh et al. [41] proposed an extension to economic order quantity model with partial backordering and reparable products. Some other recent inventory models that considered imperfect quality items are Wahab et

al. [42], Sarkar [43], Hsu \& Hsu [44], Chang [45], Jaber et al. [46], Rezaei \& Salimi [47], and Taleizadeh et al. [48].

This paper extends Salameh and Jaber [27] model to an integrated production inventory model with defective items. We assume that the integrated policy for the proposed model is accepted by the vendor and the buyer. To maintain a long-term cooperation, the vendor would deliver $100 \%$ good products to the buyer. In addition, as shown in Rezaei and Salimi [47], conducting the inspection process by the buyer may not be a cost-efficient strategy. We investigate that the products are screened by the vendor while some literature such as Huang [10] and $\mathrm{Wu}$ et al. [49] assumed that the buyer conducted inspection process whenever receiving products. We relax the assumption of defective items removed from stock after screening to allow the defective items be scrapped by multiple disposals during the production period.

The paper is organized into five sections. Section 1 provided an introduction. The notation and assumptions for this study are stated in Section 2. The model description, formulation, and solution procedure are presented in Section 3. Section 4 provides the numerical examples to illustrate the solution procedure for determining the optimum. Conclusions and suggestions for future research are given in Section 5 .

\section{Notation and assumptions}

We summarize the notation used in this study as follows:

$T$

$P$

$D$

$Q$

$n$

$S_{V}$

$S_{B} \quad$ Fixed ordering cost per order

$h_{V} \quad$ Stock-holding cost for the vendor per unit per year

$h_{B} \quad$ Stock-holding cost for the buyer per

unit per year

Order cycle time

Annual constant production rate

Annual constant demand rate

Lot size of good quality items per shipment (decision variable)

Number of good quality items shipments per order cycle (decision variable) variable)

Random fraction of defective items, a random variable with a known probability density function; $0 \leq \beta<1$

Fixed production setup cost per production batch 
Fixed cost of each disposal for defective items

$g \quad$ Fixed cost of each shipment for good quality items

$T C_{M}(n, Q)$ Annual total relevant inventory cost for the vendor

$T C_{R}(n, Q)$ annual total relevant inventory cost for the buyer

$T C(N, Q) \quad$ Annual total relevant inventory cost for both parties

We make the following assumptions for this study:

1. Consider single vendor and single buyer;

2. The demand rate is known and finite;

3. The production rate is known and finite;

4. All products are $100 \%$ inspected by the vendor. We assume that the inspection is included in production process. The vendor conducts multiple disposals of the defective items without salvage value;

5. The good items are delivered to the buyer while the defective ones are disposed from the vendor's stock. Thus, to meet the demand, it is constrained by: (1$\beta) P>D$, i.e. $P>\frac{D}{1-\beta}$ (Taking the expectation, it yields $\left.P>E\left(\frac{1}{1-\beta}\right) D\right)$;

6. The cost for facilitating multiple deliveries is the responsibility of the buyer;

7. We assume that the buyer's holding cost is greater than the vendor's holding cost, i.e. $h_{B}>h_{V}$;

8. Shortages are not allowed.

\section{Model formulation}

We consider a single-vendor single-buyer integrated model where the buyer's order quantity is manufactured and delivered in multiple equal-batch shipments. From the buyer's order quantity, the vendor plans their production batch and conducts the inspection process. During the production run, the defective items are scrapped by multiple disposals from the stock. The disposal cost for the defective items is paid by the vendor. The good quality products are spited into small lot sizes that are delivered to the buyer over an inventory cycle. The buyer incurs the shipment cost in the multiple deliveries.

Figure 1 depicts the behavior of inventory levels for the vendor and the buyer. Since the fraction of defective items is $\beta$ (or the fraction of good quality items is $1-\beta)$, the vendor would produce $\frac{n Q}{1-\beta}$ units to meet the demand of $n Q$ units during an order cycle. The vendor delivers good items to the buyer who receives $n$ shipments with each lot size $Q$. Since the demand rate is $D$, the shipment interval is $\frac{Q}{D}$

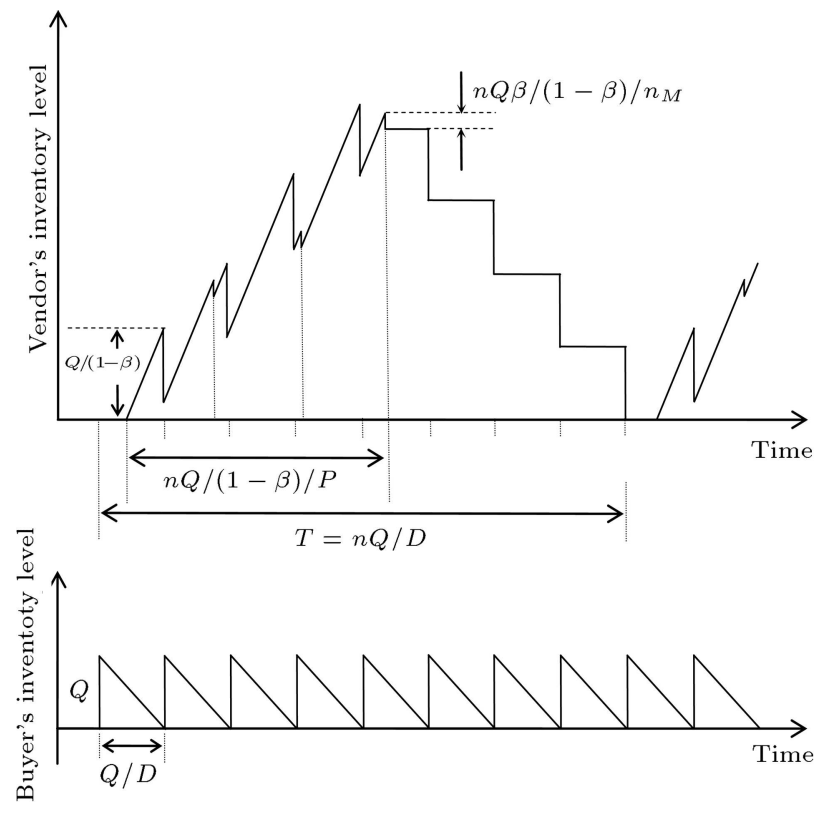

Figure 1. Vendor's and buyer's inventory levels with $n=8$ and $n_{M}=3$.

and the order cycle is $\frac{n Q}{D}$. During the production period, the $\frac{n Q \beta}{1-\beta}$ defective item units are scrapped with multiple disposals (or removals). Since the number of the disposals per cycle is $n_{M}$, the defective items unit in each disposal is $\frac{n Q \beta}{n_{M}(1-\beta)}$.

The total relevant inventory cost for an integrated inventory system includes the inventory costs from the vendor and the buyer. The vendor's cost comprises setup cost, holding cost, and disposal costs. The buyer's cost consists of ordering cost, holding cost, and shipment costs. Our purpose is to minimize the annual total relevant inventory cost for both parties, which contains the annual vendor's and buyer's costs. Subsequently, we derive different inventory costs for the vendor and the buyer.

\subsection{Vendor's inventory holding cost:}

Figure 2 shows that the vendor's holding inventory (time-weighted inventory) per order cycle can be derived by subtracting the shaded area from the bold area. The bold area includes the areas above interval $T_{1}$ and above interval $T_{2}$. Referring to Figure 2, we have:

$$
\begin{aligned}
T_{1} & =\frac{n Q}{(1-\beta) P} \\
T_{2} & =\frac{n Q}{D}-\frac{n Q}{(1-\beta) P}-\left(\frac{Q}{D}-\frac{Q}{(1-\beta) P}\right) \\
& =(n-1) Q\left(\frac{1}{D}-\frac{1}{(1-\beta) P}\right) .
\end{aligned}
$$

The bold area is derived as: 


$$
\begin{aligned}
\frac{E q \cdot(5)}{T} h_{V} & =\frac{\frac{n Q^{2}}{2 D}\left[(n-1)+\frac{2 D}{P(1-\beta)}-\frac{n D}{P(1-\beta)}+\frac{n D}{n_{M} P}\left(\frac{1}{(1-\beta)^{2}}-\frac{1}{(1-\beta)}\right)\right]}{\frac{n Q}{D}} h_{V} \\
& =\frac{Q}{2}\left[(n-1)+\frac{2 D}{P(1-\beta)}-\frac{n D}{P(1-\beta)}+\frac{n D}{n_{M} P}\left(\frac{1}{(1-\beta)^{2}}-\frac{1}{(1-\beta)}\right)\right] h_{V}
\end{aligned}
$$

\section{Box I}

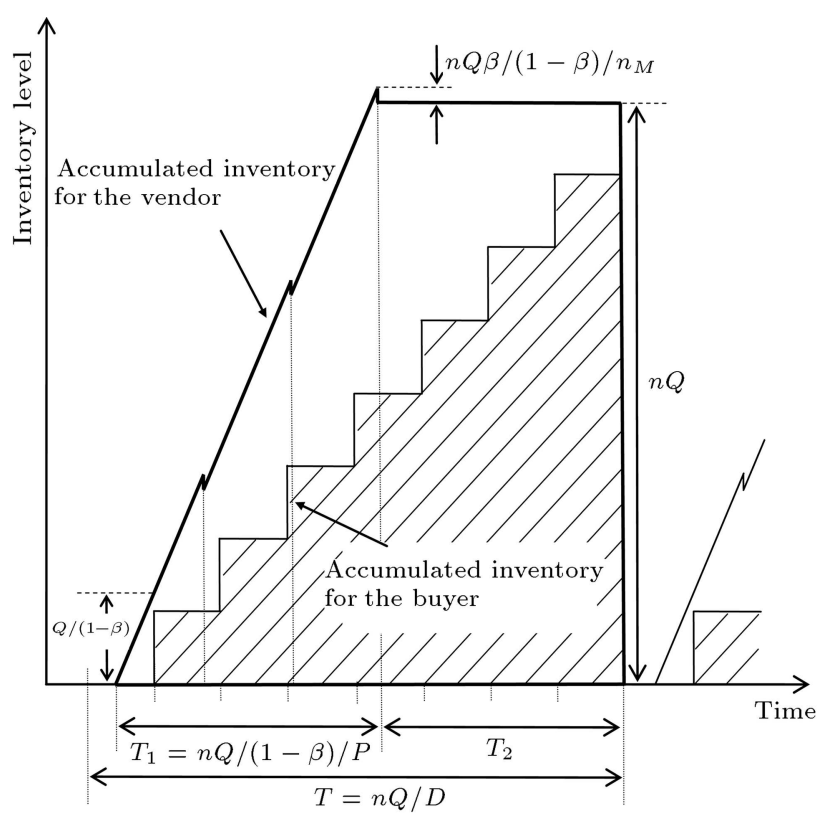

Figure 2. Vendor's accumulated inventory and buyer's accumulated inventory with $n=8$ and $n_{M}=3$.

$$
\begin{gathered}
\frac{1}{2} \frac{T_{1}}{n_{M}} \sum_{i=1}^{n_{M}}\left\{\left[(i-1) \frac{T_{1}}{n_{M}} P-(i-1) \frac{T_{1}}{n_{M}} P \beta\right]\right. \\
\left.+\left[i \frac{T_{1}}{n_{M}} P-(i-1) \frac{T_{1}}{n_{M}} P \beta\right]\right\}+n Q T_{2} \\
=\frac{n^{2} Q^{2}\left(n_{M}(1-\beta)+\beta\right)}{2(1-\beta)^{2} n_{M} P} \\
\quad+n(n-1) Q^{2}\left(\frac{1}{D}-\frac{1}{(1-\beta) P}\right) .
\end{gathered}
$$

Subsequently, the shaded area is calculated from:

$$
\begin{aligned}
& \frac{Q}{D}\{Q+2 Q+3 Q+\cdots+(n-1) Q\}=\frac{Q}{D}\left(\sum_{i=1}^{n-1} i Q\right) \\
& =\frac{n(n-1) Q^{2}}{2 D} .
\end{aligned}
$$

Subtracting shades area, Eq. (4), from bold area,
Eq. (3), we yield the vendor's holding inventory per order cycle as:

$$
\begin{gathered}
\frac{n^{2} Q^{2}\left(n_{M}(1-\beta)+\beta\right)}{2(1-\beta)^{2} n_{M} P}+n(n-1) Q^{2}\left(\frac{1}{D}-\frac{1}{(1-\beta) P}\right) \\
-\frac{n(n-1) Q^{2}}{2 D}=\frac{n Q^{2}}{2 D}\left[(n-1)+\frac{2 D}{P(1-\beta)}\right. \\
\left.-\frac{n D}{P(1-\beta)}+\frac{n D}{n_{M} P}\left(\frac{1}{(1-\beta)^{2}}-\frac{1}{(1-\beta)}\right)\right] .
\end{gathered}
$$

Thus, we can obtain the vendor's inventory holding cost per year as shown in Box I.

\subsection{Vendor's setup cost}

Since the vendor has one production per cycle time and the setup cost per production is $s_{V}$, the vendor's setup cost per year is:

$$
\frac{s_{V}}{n Q / D}=\frac{D}{n Q} s_{V} \text {. }
$$

\subsection{Vendor's disposal cost}

The number of disposals of the defective items is $n_{M}$, the cost per disposal is $u$, and the cycle time is $n Q / D$. Therefore, the disposal cost per year is:

$$
\frac{n_{M} u}{n Q / D}=\frac{n_{M} D}{n Q} u
$$

Summing costs in Eqs. (6) to (8), we derive the annual total relevant inventory cost for the vendor:

$$
\begin{aligned}
& T C_{M}\left(Q, n, n_{M}\right)=\frac{Q}{2}\left[(n-1)+\frac{2 D}{P(1-\beta)}\right. \\
& \left.\quad-\frac{n D}{P(1-\beta)}+\frac{n D}{n_{M} P}\left(\frac{1}{(1-\beta)^{2}}-\frac{1}{(1-\beta)}\right)\right] h_{V} \\
& +\frac{D}{n Q} s_{V}+\frac{n_{M} D}{n Q} u
\end{aligned}
$$




\subsection{Buyer's inventory holding cost}

Since the buyer's demand rate is constant and buyer's maximal stock level is $Q$, the buyer's average inventory is $Q / 2$. Hence, the buyer's inventory holding cost per year is:

$$
\frac{Q}{2} h_{B}
$$

\subsection{Buyer's ordering cost}

Because the buyer places an order per cycle and the cycle time is $n Q / D$, the buyer's ordering cost per year is:

$$
\frac{D}{n Q} s_{B}
$$

\subsection{Buyer's shipment cost}

Since the buyer receives $n$ shipments during a cycle time, the buyer's shipment cost per year is:

$$
\frac{D}{Q} g
$$

Summing the costs in Eqs. (10) to (12), the annual total relevant inventory cost for the buyer is:

$$
T C_{R}(Q, n)=\frac{Q}{2} h_{B}+\frac{D}{n Q} s_{B}+\frac{D}{Q} g
$$

Therefore, the annual total relevant cost for the vendor and the buyer is the sum of Eqs. (9) and (13):

$$
\begin{aligned}
T C\left(Q, n, n_{M}\right)=T C_{M}\left(Q, n, n_{M}\right)+T C_{R}(Q, n) \\
=\frac{Q}{2}\left[(n-1)+\frac{2 D}{P(1-\beta)}-\frac{n D}{P(1-\beta)}\right. \\
\left.\quad+\frac{n D}{n_{M} P}\left(\frac{1}{(1-\beta)^{2}}-\frac{1}{(1-\beta)}\right)\right] h_{V}+\frac{D}{n Q} s_{V} \\
+\frac{n_{M} D}{n Q} u+\frac{Q}{2} h_{B}+\frac{D}{n Q} s_{B}+\frac{D}{Q} g .
\end{aligned}
$$

Since $\beta$ is a random variable with a known probability density function, the expectation of $T C\left(Q, n, m_{M}\right)$ is derived as:

$$
\begin{gathered}
E\left(T C\left(Q, n, n_{M}\right)\right)=\frac{Q}{2}\left[(n-1)+\frac{2 D}{P} E_{a}-\frac{n D}{P} E_{a}\right. \\
\left.+\frac{n D}{n_{M} P}\left(E_{b}-E_{a}\right)\right] h_{V}+\frac{D}{n Q} s_{V}+\frac{n_{M} D}{n Q} u+\frac{Q}{2} h_{B}
\end{gathered}
$$

$$
+\frac{D}{n Q} s_{B}+\frac{D}{Q} g
$$

s.t.

$$
Q>0, n>0 \text { and } n_{M}>0
$$

where $E_{a}=E(1 /(1-\beta))$ and $E_{b}=E\left(1 /(1-\beta)^{2}\right)$.

Setting the number of defective item disposals $\left(n_{M}\right)$ equal to one, our model is reduced to the model with one disposal strategy for defective items. Furthermore, setting the fraction of defective items $(\beta)$ and the disposal cost $(u)$ equal to zero, the model of Eq. (15) is same as the model discussed in [50].

If $Q, n$, and $n_{M}$ are assumed to be continuous variables, the cost function of Eq. (15) is a convex function (see Appendix A for the proof). Since $n$ and $n_{M}$ are discrete variables, we develop the following approach to derive optimum. At a given set of $n$ and $n_{M}$, we first derive the optimal solution to $Q$. For the given $n$ and $n_{M}$, taking the first and second derivatives of $E\left(T C\left(Q, n, n_{M}\right)\right)$ with respect to $Q$, we have:

$$
\begin{gathered}
\frac{\partial}{\partial Q} E\left(T C\left(Q \mid n, n_{M}\right)\right)=\frac{1}{2}\left(h_{B}+(n-1) h_{V}\right. \\
\left.+\frac{D h_{V}\left(n E_{b}-\left(n+(n-2) n_{M}\right) E_{a}\right)}{n_{M} P}\right) \\
\quad-\frac{D\left(s_{B}+s_{V}+n_{M} u+n g\right)}{n Q^{2}}, \\
\frac{\partial^{2}}{\partial Q^{2}} E\left(T C\left(Q \mid n, n_{M}\right)\right) \\
=\frac{2 D\left(s_{B}+s_{V}+n_{M} u+n g\right)}{n Q^{3}}>0 .
\end{gathered}
$$

From Eq. (17), it is clear that $E\left(T C\left(Q, n, n_{M}\right)\right)$ is a convex function for $n>0$ and $n_{M}>0$. Setting Eq. (16) equal to zero, we obtain the $Q$ value that minimizes cost function as shown in Box II.

Putting Eq. (18) into Eq. (15), the total cost function will be obtained by Eq. (19) as shown in Box III.

To minimize $E\left(T C\left(n, n_{M}\right)\right)$ in Eq. (19), the algebraic calculation is simplified when we take the square of Eq. (19), since minimizing $E^{2}\left(T C\left(n, n_{M}\right)\right)$ is same as minimizing $E\left(T C\left(n, n_{M}\right)\right)$. We have Eq. (20) as shown in Box IV. Taking the first derivatives with respect to

$$
Q\left(n, n_{M}\right)=\sqrt{\frac{2 n_{M} P D\left(s_{B}+s_{V}+n_{M} u+n g\right)}{n_{M} n P h_{B}+h_{V}\left[n^{2} D\left(E_{b}-E_{a}\right)+n_{M}\left(n(n-1) P-n(n-2) D E_{a}\right)\right]}} .
$$




$$
\begin{aligned}
& E\left(T C\left(n, n_{M}\right)\right)= \\
& \frac{\left\{\sqrt{2} \sqrt{n_{M} n P h_{B}+h_{V}\left(n^{2} D\left(E_{b}-E_{a}\right)+n_{M}\left(n(n-1) P-n(n-2) D E_{a}\right)\right)} \times \sqrt{n_{M} P D\left(s_{B}+s_{V}+n_{M} u+n g\right)}\right\}}{n_{M} n P} .
\end{aligned}
$$

Box III

$$
\begin{aligned}
& E^{2}\left(T C\left(n, n_{M}\right)\right)= \\
& \frac{\left\{2\left[n_{M} P h_{B}+h_{V}\left(n D\left(E_{b}-E_{a}\right)+n_{M}\left((n-1) P-(n-2) D E_{a}\right)\right)\right] \times\left[D\left(s_{B}+s_{V}+n_{M} u+n g\right)\right]\right\}}{n_{M} n P} .
\end{aligned}
$$

Box IV

$n$ and $n_{M}$, we get:

$$
\begin{aligned}
& \frac{\partial}{\partial n} E^{2}\left(T C\left(n, n_{M}\right)\right)=2 D g h_{V} \\
& -\frac{2 D^{2} g h_{V}\left(\left(n_{M}+1\right) E_{a}-E_{b}\right)}{n_{M} P} \\
& -\frac{2 D\left(2 D E_{a} h_{V}+P\left(h_{B}-h_{V}\right)\right)\left(s_{B}+s_{V}+n_{M} u\right)}{n^{2} P},
\end{aligned}
$$

$$
\begin{aligned}
& \frac{\partial}{\partial n_{M}} E^{2}\left(T C\left(n, n_{M}\right)\right)= \\
& \frac{2 D u\left(P\left(h_{B}+(n-1) h_{V}\right)-(n-2) D E_{a} h_{V}\right)}{n P} \\
& -\frac{2 D^{2}\left(E_{b}-E_{a}\right)\left(s_{B}+s_{V}+n g\right) h_{V}}{n_{M}^{2} P}
\end{aligned}
$$

Let $n^{\#}$ and $n_{M}^{\#}$ be the solutions to $\frac{\partial}{\partial n} E^{2}(T C(n$, $\left.\left.n_{M}\right)\right)=0$ and $\frac{\partial}{\partial n_{M}} E^{2}\left(T C\left(n, n_{M}\right)\right)=0$, respectively; we have:

$$
\begin{aligned}
& n^{\#}= \\
& \sqrt{\frac{n_{M}^{\#}\left(2 D E_{a} h_{V}+P\left(h_{B}-h_{V}\right)\right)\left(s_{B}+s_{V}+n_{M}^{\#} u\right)}{g h_{V}\left(D\left(E_{b}-E_{a}\right)+n_{M}^{\#}\left(P-D E_{a}\right)\right)}}, \\
& n_{M}^{\#}= \\
& \sqrt{\frac{n^{\#} D h_{V}\left(E_{b}-E_{a}\right)\left(s_{B}+s_{V}+n^{\#} g\right)}{u\left(P h_{B}+h_{V}\left(\left(n^{\#}-1\right) P-\left(n^{\#}-2\right) D E_{a}\right)\right)}} \cdot(24)
\end{aligned}
$$

We can employ numerical search methods to solve
Eqs. (23) and (24). Alternatively, applying mathematical software such as Mathematica or Maple, we derive the following closed-form expressions of $n_{M}^{\#}$ and $n^{\#}$. Substituting $n^{\#}$ in Eq. (24) into Eq. (23) yields:

$$
n_{M}^{\#}=\sqrt{\frac{D\left(E_{b}-E_{a}\right)\left(s_{B}+s_{V}\right)}{\left(P-D E_{a}\right) u}}>0 .
$$

It can be seen that $n_{M}^{\#}$ decreases as $u$ increases. Subsequently, substituting $n_{M}^{\#}$ in Eq. (25) into Eq. (23) gives:

$$
n^{\#}=\sqrt{\frac{\left(2 D E_{a} h_{V}+P\left(h_{B}-h_{V}\right)\right)\left(s_{B}+s_{V}\right)}{\left(P-D E_{a}\right) g h_{V}}}>0 .
$$

In Appendix B, we prove the convexity of $E^{2}(T C$ $\left.\left(n, n_{M}\right)\right)$. It implies that $E\left(T C\left(n, n_{M}\right)\right)$ is also a convex function because $E^{2}\left(T C\left(n, n_{M}\right)\right)$ is derived from $E\left(T C\left(n, n_{M}\right)\right)$. We demonstrate that $n_{M}^{\#}$ and $n^{\#}$ are, respectively, equal to $n_{M C}^{*}$ in Eq. (A.7) and $n_{C}^{*}$ in Eq. (A.10) since $E\left(T C\left(n, n_{M}\right)\right)$ is the cost function with the optimal $Q$ shown in Eq. (18). Due to the assumptions of $h_{B}>h_{V}$ and $P-D E_{a}>0$, Eqs. (25) and (26) show that $n^{\#}$ and $n_{M}^{\#}$ are positive numbers minimizing $E^{2}\left(T C\left(n, n_{M}\right)\right)$ and $E\left(T C\left(n, n_{M}\right)\right)$.

Since the optimal $n$ and $n_{M}$ should be integers, although $n^{\#}$ and $n_{M}^{\#}$ are positive and not always integer numbers, optimal $n$ and $n_{M}$ values should be the integers around $n^{\#}$ and $n_{M}^{\#}$. Let $n^{\#^{-}}\left(n_{M}^{\#-}\right)$ and $n^{\#^{+}}\left(n_{M}^{\#+}\right)$, respectively, denote the minimal integers less than and greater than $n^{\#}\left(n_{M}^{\#}\right)$. Note that if $n^{\#}\left(n_{M}^{\#}\right)$ is less than one, we let $n^{\#-}=n^{\#+}=1$ $\left(n_{M}^{\#-}=n_{M}^{\#+}=1\right)$ because zero is not feasible.

Let $\left(n^{*}, n_{M}^{*}\right)$ be the optimal integer solution to $E\left(T C\left(n, n_{M}\right)\right)$. If $E\left(T C\left(n, n_{M}\right)\right)$ in $\mathrm{Eq}$. (19) is 
minimized, we have:

$$
\begin{aligned}
& E\left(T C\left(n^{*}, n_{M}^{*}\right)\right)=\operatorname{Min}\left\{E\left(T C\left(n^{\#-}, n_{M}^{\#-}\right)\right),\right. \\
& E\left(T C\left(n^{\#-}, n_{M}^{\#+}\right)\right), E\left(T C\left(n^{\#+}, n_{M}^{\#-}\right)\right), \\
& \left.E\left(T C\left(n^{\#+}, n_{M}^{\#+}\right)\right)\right\}
\end{aligned}
$$

where:

$$
\begin{gathered}
\left(n^{*}, n_{M}^{*}\right) \in\left\{\left(n^{\#-}, n_{M}^{\#-}\right),\left(n^{\#-}, n_{M}^{\#+}\right),\right. \\
\left.\left(n^{\#+}, n_{M}^{\#-}\right),\left(n^{\#+}, n_{M}^{\#+}\right)\right\} .
\end{gathered}
$$

Substituting $\left(n^{*}, n_{M}^{*}\right)$ for $\left(n, n_{M}\right)$ in Eq. (18), the optimal shipment quantity is derived by Eq. (28) as shown in Box V.

The following solution procedure is provided to derive the optimal solution.

1. Compute $n_{M}^{\#}$ and $n^{\#}$ from Eqs. (25) and (26), respectively. The values of $n^{\#-}, n^{\#+}, n_{M}^{\#-}$, and $n_{M}^{\#+}$ are obtained. If $n_{M}^{\#}\left(n^{\#}\right)$ is less than one, then $n_{M}^{\#-}=n_{M}^{\#+}=1\left(n^{\#-}=n^{\#+}=1\right)$;

2. Derive the optimal solution to $\left(n, n_{M}\right)$ :

$$
\begin{gathered}
\left(n^{*}, n_{M}^{*}\right) \in\left\{\left(n^{\#-}, n_{M}^{\#-}\right),\left(n^{\#-}, n_{M}^{\#+}\right),\right. \\
\left.\left(n^{\#+}, n_{M}^{\#-}\right),\left(n^{\#+}, n_{M}^{\#+}\right)\right\},
\end{gathered}
$$

which results in the lowest cost decided from Eq. (27);

3. From Eq. (18) or (28), the optimal shipment quantity is derived, i.e. $Q^{*}=Q\left(n^{*}, n_{M}^{*}\right)$.

\section{Numerical example}

To illustrate the proposed model, we provide the following examples:

Example 1. The imperfect fraction in each pro- duction batch follows a uniform distribution with the following probability density function:

$$
f(\beta)= \begin{cases}25, & 0 \leq \beta \leq 0.04 \\ 0, & \text { otherwise }\end{cases}
$$

The parameter values are as follows:

- Production rate: $P=48,000$ (unit/year)

- Demand rate: $D=12,000$ (unit/year)

- Vendor's setup cost: $S_{V}=500$ (\$/setup)

- Vendor's holding cost: $h_{V}=10$ (\$/unit/year)

- Vendor's disposal cost: $u=50$ (\$/disposal)

- Buyer's order cost: $S_{B}=25$ (\$/order)

- Buyer's holding cost: $h_{B}=12$ (\$/unit/year)

- Buyer's shipment cost: $g=25$ ( $\$ /$ shipment)

Compute the expectation values:

$$
\begin{aligned}
& E_{a}=E\left(\frac{1}{1-\beta}\right)=1.0206, \\
& E_{b}=E\left(\frac{1}{(1-\beta)^{2}}\right)=1.0417 .
\end{aligned}
$$

In Figure 3, we first illustrate that Eq. (19) is a convex function. The optimal solutions are derived through the following procedures.

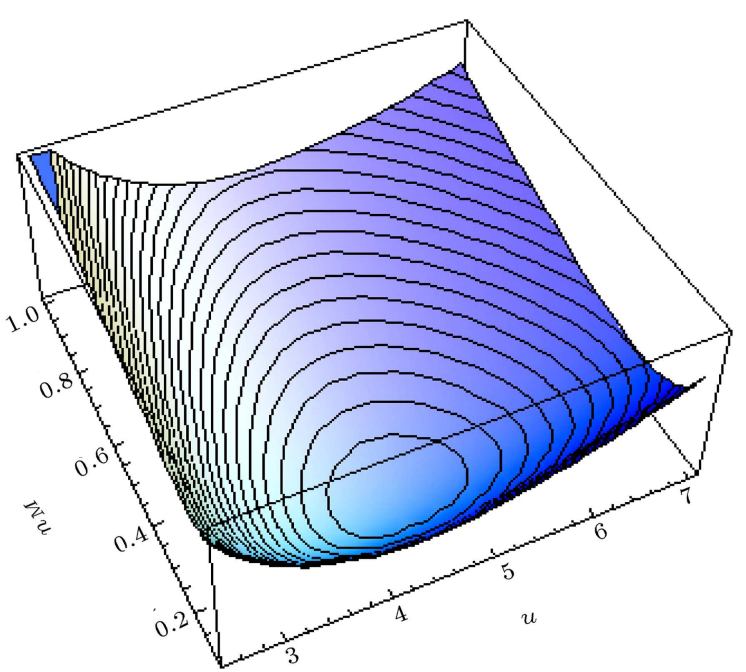

Figure 3. The graphic diagram for the integrated total relevant cost in Example 1.

$$
Q\left(n^{*}, n_{M}^{*}\right)=\sqrt{\frac{2 n_{M}^{*} P D\left(s_{B}+s_{V}+n_{M}^{*} u+n^{*} g\right)}{n_{M}^{*} n^{*} P h_{B}+h_{V}\left[n^{* 2} D\left(E_{b}-E_{a}\right)+n_{M}^{*}\left(n^{*}\left(n^{*}-1\right) P-n^{*}\left(n^{*}-2\right) D E_{a}\right)\right]}} .
$$


From Eqs. (25) and (26), we get:

$$
\begin{aligned}
& n^{\#}=\sqrt{\frac{\left(2 D E_{a} h_{V}+P\left(h_{B}-h_{V}\right)\right)\left(s_{B}+s_{V}\right)}{\left(P-D E_{a}\right) g h_{V}}}=4.48, \\
& n_{M}^{\#}=\sqrt{\frac{D\left(E_{b}-E_{a}\right)\left(s_{B}+s_{V}\right)}{\left(P-D E_{a}\right) u}}=0.27,
\end{aligned}
$$

which give $n^{\#^{-}}=4, n^{\#^{+}}=5$, and $n_{M}^{\#-}=n_{M}^{\#+}=1$.

Using Eq. (19), we calculate:

$$
\begin{gathered}
E\left(T C\left(n^{\#-}, n_{M}^{\#-}\right)\right)=E\left(T C\left(n^{\#-}, n_{M}^{\#+}\right)\right) \\
=E(T C(4,1))=\$ 12,259.2, \\
E\left(T C\left(n^{\#+}, n_{M}^{\#-}\right)\right)=E\left(T C\left(n^{\#+}, n_{M}^{\#+}\right)\right) \\
=E(T C(5,1))=\$ 12,242.9 .
\end{gathered}
$$

Therefore, we have the optimal solution: $\left(n^{*}, n_{M}^{*}\right)=$ $(5,1)$, which results in the lowest total relevant cost of $E\left(T C\left(n^{*}, n_{M}^{*}\right)\right)=\$ 12,242.9$.

From Eq. (28), the optimal shipment size is $Q^{*}=$ $Q\left(n^{*}, n_{M}^{*}\right)=274.44$.

As mentioned in Section 2, by assuming the fraction of defective items: $\beta=0$, the disposal cost: $u=0$, and the number of defective item disposals: $n_{M}=1$, the cost function of Eq. (15) reduces to the one without considering defective items. For the case of no defective items, we show how our model derives the optimum as follows.

Give the fraction of defective items: $\beta=0$ (i.e., $E_{a}=E_{b}=1$ ) and the disposal cost: $u=0$ for this example. We derive:

$$
n^{\#}=\sqrt{\frac{\left(2 D E_{a} h_{V}+P\left(h_{B}-h_{V}\right)\right)\left(s_{B}+s_{V}\right)}{\left(P-D E_{a}\right) g h_{V}}}=4.43 .
$$

We subsequently set: $n_{M}^{\#}=1$. Then, we obtain: $n^{\#^{-}}=4, n^{\#^{+}}=5, n_{M}^{\#^{-}}=n_{M}^{\#^{+}}=1$. We calculate:

$$
\begin{gathered}
E\left(T C\left(n^{\#-}, n_{M}^{\#-}\right)\right)=E\left(T C\left(n^{\#-}, n_{M}^{\#+}\right)\right) \\
=E(T C(4,1))=\$ 11,779.2, \\
E\left(T C\left(n^{\#+}, n_{M}^{\#-}\right)\right)=E\left(T C\left(n^{\#+}, n_{M}^{\#+}\right)\right) \\
=E(T C(5,1))=\$ 11,783.0 .
\end{gathered}
$$

Therefore, we derive the optimal number of shipments: $n^{*}=4$, which results in the lowest total relevant cost $\$ 11,779.2$. The optimal shipment size is $Q^{*}=$ $Q(4,1)=318.36$ and the optimal order size is $4 \times$ $318.36=1,273.44$, which are the same as the results discussed in [50].

We subsequently discuss a policy for which the buyer optimizes the shipment lot size that is provided for the vendor. Using the optimal shipment size, the vendor then determines the optimal numbers of shipment and disposal. For distinction, the above-mentioned policy is called "non-integrated". In Eq. (15), we see that the vendor's and buyer's costs are:

$$
\begin{aligned}
& \frac{Q}{2}\left[(n-1)+\frac{2 D}{P} E_{a}-\frac{n D}{P} E_{a}+\frac{n D}{n_{M} P}\left(E_{b}-E_{a}\right)\right] h_{V} \\
& \quad+\frac{D}{n Q} s_{V}+\frac{n_{M} D}{n Q} u,
\end{aligned}
$$

and:

$$
\frac{Q}{2} h_{B}+\frac{D}{n Q} s_{B}+\frac{D}{Q} g
$$

respectively.

From Eq. (30), we derive the optimal shipment lot size:

$$
\sqrt{\frac{2 D\left(s_{B}+n g\right)}{n h_{B}}}
$$

Substituting $Q$ by Eq. (31) into Eq. (29), we obtain the optimal $\left(n, n_{M}\right)$, which minimizes the vendor's cost. The optimal solutions to the integrated and the nonintegrated policies are shown in Table 1. It is shown that the two policies have the same optimal $\left(n, n_{M}\right)$. With a lower optimal shipment size for the buyer, the non-integrated policy leads to a lower buyer's cost than the integrated policy does. This comparison reveals that the integrated policy results in a lower total inventory cost for both parties.

The effects of cost parameter values on the optimal policy for Example 1 are provided in Tables 2-7. Table 2 shows that the optimal number of shipments per order cycle slightly increases as the vendor's setup cost increases. When the vendor's setup cost significantly increases, the production lot size per cycle (i.e., $n Q)$ will increase in this example. Table 3 indicates that optimal number of shipments is not sensitive to

Table 1. The results for Example 1 with integrated and non-integrated policies.

\begin{tabular}{lccccc}
\hline & $\left(\boldsymbol{n}^{*}, \boldsymbol{n}_{\boldsymbol{M}}^{*}\right)$ & $\boldsymbol{Q}^{*}$ & $\boldsymbol{E}\left(\boldsymbol{T} \boldsymbol{C}_{\boldsymbol{M}}\left(\boldsymbol{Q}, \boldsymbol{n}, \boldsymbol{n}_{\boldsymbol{M}}\right)\right)$ & $\boldsymbol{E}\left(\boldsymbol{T} \boldsymbol{C}_{\boldsymbol{R}}(\boldsymbol{Q})\right)$ & $\boldsymbol{E}\left(\boldsymbol{T} \boldsymbol{C}\left(\boldsymbol{n}^{*}, \boldsymbol{n}_{\boldsymbol{M}}^{*}\right)\right)$ \\
\hline Integrated & $(5,1)$ & 274.44 & $\$ 9,284.5$ & $\$ 2,958.4$ & $\$ 12,242.9$ \\
Non-integrated & $(5,1)$ & 244.95 & $\$ 9,382.8$ & $\$ 2,939.4$ & $\$ 12,322.2$ \\
\hline
\end{tabular}


Table 2. The optimal solutions for Example 1 with different $S_{V}$ values.

\begin{tabular}{cccccc}
\hline \multicolumn{5}{c}{$\boldsymbol{P}=\mathbf{4 8}, \mathbf{0 0 0}, \boldsymbol{D}=\mathbf{1 2}, \mathbf{0 0 0}, \boldsymbol{h}_{\boldsymbol{V}}=\mathbf{1 0}, \boldsymbol{u}=\mathbf{5 0}, \boldsymbol{S}_{\boldsymbol{B}}=\mathbf{2 5}, \boldsymbol{h}_{\boldsymbol{B}}=\mathbf{1 2}, \boldsymbol{g}=\mathbf{2 5}$} \\
\hline Vendor's set up cost $\left(\boldsymbol{S}_{\boldsymbol{V}}\right)$ & $\mathbf{3 0 0}$ & $\mathbf{4 0 0}$ & $\mathbf{5 0 0}$ & $\mathbf{6 0 0}$ & $\mathbf{7 0 0}$ \\
\hline$\left(n^{*}, n_{M}^{*}\right)$ & $(4,1)$ & $(4,1)$ & $(5,1)$ & $(5,1)$ & $(5,1)$ \\
$Q^{*}$ & 277.13 & 304.91 & 274.44 & 293.39 & 311.19 \\
$E\left(T C\left(n^{*}, n_{M}^{*}\right)\right)$ & 10283.9 & $\$ 11,314.8$ & $\$ 12,242.9$ & $\$ 13,088.2$ & $\$ 13,882.2$ \\
\hline
\end{tabular}

Table 3. The optimal solutions for Example 1 with different $S_{B}$ values.

\begin{tabular}{cccccc}
\hline \multicolumn{5}{c}{$\boldsymbol{P}=\mathbf{4 8}, \mathbf{0 0 0}, \boldsymbol{D}=\mathbf{1 2}, \mathbf{0 0 0}, \boldsymbol{h}_{\boldsymbol{V}}=\mathbf{1 0}, \boldsymbol{u}=\mathbf{5 0}, \boldsymbol{S}_{\boldsymbol{B}}=\mathbf{2 5}, \boldsymbol{h}_{\boldsymbol{B}}=\mathbf{1 2}, \boldsymbol{g}=\mathbf{2 5}$} \\
\hline Buyer's order cost $\left(\boldsymbol{S}_{\boldsymbol{B}}\right)$ & $\mathbf{1 5}$ & $\mathbf{2 0}$ & $\mathbf{2 5}$ & $\mathbf{3 0}$ & $\mathbf{3 5}$ \\
\hline$\left(n^{*}, n_{M}^{*}\right)$ & $(5,1)$ & $(5,1)$ & $(5,1)$ & $(5,1)$ & $(5,1)$ \\
$Q^{*}$ & 272.48 & 273.46 & 274.44 & 275.42 & 276.40 \\
$E\left(T C\left(n^{*}, n_{M}^{*}\right)\right)$ & $\$ 12,155.2$ & $\$ 12,199.1$ & $\$ 12,242.9$ & $\$ 12,286.6$ & $\$ 12,330.1$ \\
\hline
\end{tabular}

Table 4. The optimal solutions for Example 1 with different $h_{V}$ values.

\begin{tabular}{cccccc}
\hline \multicolumn{5}{c}{$\boldsymbol{P}=\mathbf{4 8}, \mathbf{0 0 0}, \boldsymbol{D}=\mathbf{1 2}, \mathbf{0 0 0}, \boldsymbol{u}=\mathbf{5 0}, \boldsymbol{S}_{\boldsymbol{V}}=\mathbf{5 0 0}, \boldsymbol{S}_{\boldsymbol{B}}=\mathbf{2 5}$} & $\boldsymbol{h}_{\boldsymbol{B}}=\mathbf{1 2}, \boldsymbol{g}=\mathbf{2 5}$ \\
\hline Vendor's holding cost $\left(\boldsymbol{h}_{\boldsymbol{V}}\right)$ & $\mathbf{8}$ & $\mathbf{9}$ & $\mathbf{1 0}$ & $\mathbf{1 1}$ & $\mathbf{1 2}$ \\
\hline$\left(n^{*}, n_{M}^{*}\right)$ & $(6,1)$ & $(5,1)$ & $(5,1)$ & $(4,1)$ & $(4,1)$ \\
$Q^{*}$ & 256.47 & 285.06 & 274.44 & 319.72 & 310.05 \\
$E\left(T C\left(n^{*}, n_{M}^{*}\right)\right)$ & $\$ 11,307.4$ & $\$ 11,786.9$ & $\$ 12,242.9$ & $\$ 12,667.2$ & $\$ 13,062.4$ \\
\hline
\end{tabular}

Table 5. The optimal solutions for Example 1 with different $h_{B}$ values.

\begin{tabular}{cccccc}
\hline \multicolumn{2}{r}{$=\mathbf{4 8 , 0 0 0}, \boldsymbol{D}=\mathbf{1 2}, \mathbf{0 0 0}, \boldsymbol{u}=\mathbf{5 0}, \boldsymbol{h}_{\boldsymbol{V}}=\mathbf{1 0}, \boldsymbol{u}=\mathbf{5 0}, \boldsymbol{S}_{\boldsymbol{V}}=\mathbf{5 0 0} \boldsymbol{S}_{\boldsymbol{B}}=\mathbf{2 5}, \boldsymbol{g}=\mathbf{2 5}$} \\
\hline Buyer's holding cost $\left(\boldsymbol{h}_{\boldsymbol{B}}\right)$ & $\mathbf{1 0}$ & $\mathbf{1 1}$ & $\mathbf{1 2}$ & $\mathbf{1 3}$ & $\mathbf{1 4}$ \\
\hline$\left(n^{*}, n_{M}^{*}\right)$ & $(4,1)$ & $(4,1)$ & $(5,1)$ & $(5,1)$ & $(5,1)$ \\
$Q^{*}$ & 339.64 & 334.91 & 274.44 & 271.42 & 268.49 \\
$E\left(T C\left(n^{*}, n_{M}^{*}\right)\right)$ & $\$ 11,924.3$ & $\$ 12,092.9$ & $\$ 12,242.9$ & $\$ 12,379.4$ & $\$ 12,514.4$ \\
\hline
\end{tabular}

Table 6. The optimal solutions for Example 1 with different $u$ values.

\begin{tabular}{|c|c|c|c|c|c|}
\hline \multicolumn{6}{|c|}{$P=48,000, D=12,000, h_{V}=10, S_{V}=500 S_{B}=25, h_{B}=12, g=25$} \\
\hline Vendor's disposal cost $(u)$ & 0.1 & 1 & 50 & 100 & 200 \\
\hline$\left(n^{*}, n_{M}^{*}\right)$ & $(5,6)$ & $(5,2)$ & $(5,1)$ & $(5,1)$ & $(5,1)$ \\
\hline$Q^{*}$ & 265.24 & 265.26 & 274.44 & 284.08 & 302.42 \\
\hline$E\left(T C\left(n^{*}, n_{M}^{*}\right)\right)$ & $\$ 11,773.9$ & $\$ 11,798.2$ & $\$ 12,242.9$ & $\$ 12,672.6$ & $\$ 13,491.0$ \\
\hline
\end{tabular}

Table 7. The optimal solutions for Example 1 with different $g$ values.

\begin{tabular}{cccccc}
\hline \multicolumn{5}{c}{$\boldsymbol{P}=\mathbf{4 8}, \mathbf{0 0 0}, \boldsymbol{D}=\mathbf{1 2}, \mathbf{0 0 0}, \boldsymbol{h}_{\boldsymbol{V}}=\mathbf{1 0}, \boldsymbol{u}=\mathbf{5 0}, \boldsymbol{S}_{\boldsymbol{V}}=\mathbf{5 0 0} \boldsymbol{S}_{\boldsymbol{B}}=\mathbf{2 5}, \boldsymbol{h}_{\boldsymbol{B}}=\mathbf{1 2}$} \\
\hline Buyer's shipment cost $(\boldsymbol{g})$ & $\mathbf{5}$ & $\mathbf{1 5}$ & $\mathbf{2 5}$ & $\mathbf{3 5}$ & $\mathbf{4 5}$ \\
\hline$\left(n^{*}, n_{M}^{*}\right)$ & $(10,1)$ & $(6,1)$ & $(5,1)$ & $(4,1)$ & $(4,1)$ \\
$Q^{*}$ & 135.15 & 225.93 & 274.44 & 340.01 & 349.39 \\
$E\left(T C\left(n^{*}, n_{M}^{*}\right)\right)$ & $\$ 11,098.4$ & $\$ 11,773.5$ & $\$ 12,242.9$ & $\$ 12,617.3$ & $\$ 12,965.4$ \\
\hline
\end{tabular}

the buyer's ordering cost. It is obvious that the optimal number of shipments will increase when the buyer's ordering cost (the vendor's setup cost) increases. In Table 4, one can see that a larger vendor's holding cost results in a smaller optimal number of shipments.
Table 5 reveals that the buyer would like a larger number of shipments when the buyer's holding cost is larger. From Table 6, it can be seen that when the disposal cost is low, the vendor will benefit from increasing the number of disposals. Table 7 concludes 
that the optimal number of shipments decreases as the buyer's shipment cost increases.

Example 2. The imperfect fraction in each production batch is same as that in Example 1. The parameter values are as follows:

- Production rate: $P=3,200$ (unit/year)

- Demand rate: $D=1,000$ (unit/year)

- Vendor's setup cost: $S_{V}=400(\$ /$ setup $)$

- Vendor's holding cost: $h_{V}=4$ (\$/unit/year)

- Vendor's disposal cost: $u=14$ ( $\$ /$ disposal)

- Buyer's order cost: $S_{B}=0$ ( $\$ /$ order)

- Buyer's holding cost: $h_{B}=5$ ( $\$ /$ unit/year)

- Buyer's shipment cost: $g=25$ (\$/shipment)

We have $E_{a}=1.0206$ and $E_{b}=1.0417$, like those in Example 1.

From Eqs. (25) and (26), we obtain: $n^{\#}=4.57$ and $n_{M}^{\#}=1.97$, which give $n^{\#^{-}}=4, n^{\#^{+}}=5, n_{M}^{\#-}=$ 1 , and $n_{M}^{\#+}=2$.

From Eq. (19), we calculate:

$$
\begin{aligned}
& E\left(T C\left(n^{\#-}, n_{M}^{\#-}\right)\right)=E(T C(4,1))=\$ 1,909.4, \\
& E\left(T C\left(n^{\#-}, n_{M}^{\#+}\right)\right)=E(T C(4,2))=\$ 1,907.8, \\
& E\left(T C\left(n^{\#+}, n_{M}^{\#-}\right)\right)=E(T C(5,1))=\$ 1,908.1, \\
& E\left(T C\left(n^{\#+}, n_{M}^{\#+}\right)\right)=E(T C(5,2))=\$ 1,906.3 .
\end{aligned}
$$

Therefore, we derive the optimal solution: $\left(n^{*}, n_{M}^{*}\right)=$ $(5,2)$, which results in the lowest total relevant cost of $E\left(T C\left(n^{*}, n_{M}^{*}\right)\right)=\$ 1,906.3$. From Eq. (28), the optimal shipment size is derived as: $Q^{*}=Q\left(n^{*}, n_{M}^{*}\right)=$ 110.58 .

We subsequently consider this example without defective items. Setting the fraction of defective items: $\beta=0$ (i.e., $E_{a}=E_{b}=1$ ) and the disposal cost: $u=0$, we derive:

$$
n^{\#}=\sqrt{\frac{\left(2 D E_{a} h_{V}+P\left(h_{B}-h_{V}\right)\right)\left(s_{B}+s_{V}\right)}{\left(P-D E_{a}\right) g h_{V}}}=4.51 .
$$

Set $n_{M}^{\#}=1$. Therefore, we have: $n^{\#^{-}}=4, n^{\#^{+}}=$ $5, n_{M}^{\#-} n_{M}^{\#+}=1$. Then, we calculate:

$$
\begin{gathered}
E\left(T C\left(n^{\#-}, n_{M}^{\#-}\right)\right)=E\left(T C\left(n^{\#-}, n_{M}^{\#+}\right)\right) \\
=E(T C(4,1))=\$ 1,903.94,
\end{gathered}
$$

$$
\begin{gathered}
E\left(T C\left(n^{\#+}, n_{M}^{\#-}\right)\right)=E\left(T C\left(n^{\#+}, n_{M}^{\#+}\right)\right) \\
=E(T C(5,1))=\$ 1,903.29
\end{gathered}
$$

The optimal number of shipments, which results in the lowest total relevant cost $\$ 1,903.29$, is $n^{*}=5$. The optimal shipment size is $Q^{*}=Q(5,1)=110.34$ and the optimal order size is $5 \times 110.34=551.70$. Our result is same as the result using the equal-size batch policy in Hill [7].

\section{Conclusions}

This study presents an integrated vendor-buyer inventory model with defective items. While some literature assumed products screened by the buyer and defective items removed after inspection process, our proposed model considered the vendor responsible to conduct quality inspection. A random fraction of defective items was produced by the vendor who implemented a $100 \%$ inspection to screen the defective units, which were scrapped by multiple disposals during the screening period. The multiple disposals strategy provides the vendor with a flexible treatment to scrap defective items. To minimize the integrated cost, the mathematical model was formulated to derive the closed-form optimal solutions to the order quantity, the number of shipments, and the number of defective item disposals. We proved that the function of annual cost was convex. The examples illustrated the solution procedure and compared our results with related models in the literature. The sensitivity analysis was provided to show how the cost parameters affected the optimal solution. If the disposal cost is relatively low, it may be better to scrap defective items by the multiple disposals strategy.

Future research directions are open to consider unequal-size shipment policies and to incorporate quantity discount or return policy. Moreover, our study can be extended to models in which the screening rate is different from the production rate, and the defective items are reworked during the same production cycle.

\section{References}

1. Goyal, S.K. "An integrated inventory model for a single supplier-single customer problem", International Journal of Production Research, 14, pp. 107-111 (1976).

2. Banerjee, A. "A joint economic-lot-size model for purchaser and vendor", Decision Science, 17, pp. 292311 (1986).

3. Goyal, S.K. "A joint economic-lot-size model for purchaser and vendor: a comment", Decision Science, 19, pp. 236-241 (1988). 
4. Lu, L. "A one-vendor multi-buyer integrated inventory model", European Journal of Operational Research, 81, pp. 312-323 (1995).

5. Goyal, S.K. "A one vendor multi-buyer integrated inventory model: a comment", European Journal of Operational Research, 82, pp. 209-210 (1995).

6. Hill, R.M. "The single-vendor single-buyer integrated production-inventory model with a generalized policy", European Journal of Operational Research, 97, pp. 493-499 (1997).

7. Hill, R.M. "The optimal production and shipment policy for the single-vendor single-buyer integrated production-inventory problem", International Journal of Production Research, 37, pp. 2463-2475 (1999).

8. Goyal, S.K. and Nebebe, F. "Determination of economic production-shipment policy for a single-vendorsingle-buyer system", European Journal of Operational Research, 121, pp. 175-178 (2000).

9. Hill, R.M. and Omar, M. "Another look at the singlevendor single-buyer integrated inventory productioninventory problem", International Journal of Production Research, 44, pp. 791-800 (2006).

10. Huang, C.K. "An optimal policy for a single-vendor single-buyer integrated production-inventory problem with process unreliability consideration", International Journal of Production Economics, 91, pp. 91-98 (2004).

11. Nieuwenhuyse, I.V. and Vandaele, N. "The impact of delivery lot splitting on delivery reliability in a twostage supply chain", International Journal of Production Economics, 104, pp. 694-708 (2006).

12. Ertogral, K., Darwish, M., and Ben-Daya, M. "Production and shipment lot sizing in a vendor-buyer supply chain with transportation cost", European Journal of Operational Research, 176, pp. 1592-1606 (2007).

13. Lin, Y.J. "An integrated vendor-buyer inventory model with backorder price discount and effective investment to reduce ordering cost", Computers and Industrial Engineering, 56, pp. 1597-1606 (2009).

14. Sajadieh, M.S., Thorstenson, A., and Jokar, M.R.A. "An integrated vendor-buyer model with stockdependent demand", Transportation Research: Part E: Logistics and Transporation Review, 46(6), pp. 963-974 (2010).

15. Sari, D.P., Rusdiansyah, A., and Huang, L. "Models of joint economic lot-sizing problem with time-based temporary price discounts", International Journal of Production Economics, 139, pp. 145-154 (2012).

16. Glock, C.H. "The joint economic lot size problem: A review", International Journal of Production Economics, 135(2), pp. 671-686 (2012).

17. Rad, M.A., Khoshalhan, F., and Glock, C.H. "Optimizing inventory and sales decisions in a two-stage supply chain with imperfect production and backorders", Computers and Industrial Engineering, 74, pp. 219227 (2014).
18. Lee, S.D. and Fu, Y.C. "Joint production and delivery lot sizing for a make-to-order producer-buyer supply chain with transportation cost", Transportation Research Part E: Logistics and Transportation Review, 66, pp. 23-35 (2014).

19. Sarakhsi, M.K., Ghomi, S.F., and Karimi, B. "Joint economic lot-sizing problem for a two-stage supply chain with price-sensitive demand", Scientia Iranica. Transaction E, Industrial Engineering, 23(3), pp. 1474-1487 (2016).

20. Lin, T.Y. "Coordination policy for a two-stage supply chain considering quantity discounts and overlapped delivery with imperfect quality", Computers \& Industrial Engineering, 66(1), pp. 53-62 (2013).

21. Yi, H. and Sarker, B.R. "An operational policy for an integrated inventory system under consignment stock policy with controllable lead time and buyers' space limitation", Computers \& Operations Research, 40, pp. 2632-2645 (2013).

22. Wee, H.M. and Widyadana, G.A. "Single-vendor single-buyer inventory model with discrete delivery order, random machine unavailability time and lost sales", International Journal of Production Economics, 143(2), pp. 574-579 (2013).

23. Ouyang, L.-Y., Chen, L.-Y., and Yang, C.-T. "Impacts of collaborative investment and inspection policies on the integrated inventory model with defective items", International Journal of Production Research, 51(19), pp. 5789-5802 (2013).

24. Giri, B.C. and Sharma, S. "Lot sizing and unequalsized shipment policy for an integrated productioninventory system", International Journal of Systems Science, 45(5), pp. 888-901 (2014).

25. Chung, K.J., Lin, T.Y., and Srivastava, H.M. "An alternative solution technique of the JIT lot-splitting model for supply chain management", Applied Mathematics \& Information Sciences, 9(2), pp. 583-591 (2015).

26. Rosenblatt, M.J. and Lee, H.L. "Economic production cycles with imperfect production processes", IIE Transactions, 18, pp. 48-55 (1986).

27. Salameh, M.K. and Jaber, M.Y. "Economic production quantity model for items with imperfect quality", International Journal of Production Economics, 64, pp. 59-64 (2000).

28. Wee, H.M., Yu, J., and Chen, M.C. "Optimal inventory model for items with imperfect quality and shortage backordering", Omega, 35, pp. 7-11 (2007).

29. Eroglu, A. and Ozdemir, G. "An economic order quantity model with defective items and shortages", International Journal of Production Economics, 106, pp. 544-549 (2007).

30. Chang, H.C. and Ho, C.H. "Exact closed-form solutions for optimal inventory model for items with imperfect quality and shortage backordering", Omega, 38(3-4), pp. 233-237 (2010). 
31. Hsu, W.K.K. and Yu, H.F. "EOQ model for imperfective items under a one-time-only discount", Omega, 37(5), pp. 1018-1026 (2009).

32. Maddah, B., Salameh, M.K., and Moussawi, L. "Order overlapping: a practical approach for preventing shortages during screening", Computers and Industrial Engineering, 58(4), pp. 691-695 (2010).

33. Khan, M., Jaber, M.Y., Guiffrida, A.L., and Zolfaghari, S. "A review of the extensions of a modified EOQ model for imperfect quality items", International Journal of Production Economics, 132, pp. 1-12 (2011).

34. Chang, H.J., Su, R.H., Yang, C.T., and Weng, M.W. "An economic manufacturing quantity model for a two-stage assembly system with imperfect processes and variable production rate", Computers \& Industrial Engineering, 63(1), pp. 285-293 (2012).

35. Yassine, A., Maddah, B., and Salameh, M. "Disaggregation and consolidation of imperfect quality shipments in an extended EPQ model", International Journal of Production Economics, 135, pp. 345-352 (2012).

36. Rezaei, J. and Davoodi, M. "A deterministic, multiitem inventory model with supplier selection and imperfect quality", Applied Mathematical Modelling, 32(10), pp. 2106-2116 (2008).

37. Rezaei, J. and Davoodi, M. "A joint pricing, lot-sizing, and supplier selection model", International Journal of Production Research, 50(16), pp. 4524-4542 (2012).

38. Moussawi-Haidar, L., Salameh, M., and Nasr, W. "An instantaneous replenishment model under the effect of a sampling policy for defective items", Applied Mathematical Modelling, 37(3), pp. 719-727 (2013).

39. Rezaei, J. "Economic order quantity and sampling inspection plans for imperfect items", Computers \& Industrial Engineering, 96, pp. 1-7 (2016).

40. Hsu, L.F. and Hsu, J.T. "Economic production quantity (EPQ) models under an imperfect production process with shortages backordered", International Journal of Systems Science, 47(4), pp. 852-867 (2016).

41. Taleizadeh, A.A., Khanbaglo, M.P.S., and CárdenasBarrón, L.E. "An EOQ inventory model with partial backordering and reparation of imperfect products", International Journal of Production Economics, 182, pp. 418-434 (2016).

42. Wahab, M.I.M., Mamun, S.M.H., and Ongkunaruk, P. "EOQ models for a coordinated two-level international supply chain considering imperfect items and environmental impact", International Journal of Production Economics, 134(1), pp. 151-158 (2011).

43. Sarkar, B. "An EOQ model with delay in payments and stock dependent demand in the presence of imperfect production", Applied Mathematics and Computation, 218(17), pp. 8295-8308 (2012).

44. Hsu, J.-T. and Hsu, L.-F. "An EOQ model with imperfect quality items, inspection errors, shortage backordering, and sales returns", International Jour- nal of Production Economics, 143(1), pp. 162-170 (2013).

45. Chang, H.-C. "An economic production quantity model with consolidating shipments of imperfect quality items: A note", International Journal of Production Economics, 144(2), pp. 507-509 (2013).

46. Jaber, M.Y., Zanoni, S., and Zavanella, L.E. "Economic order quantity models for imperfect items with buy and repair options", International Journal of Production Economics, 155, pp. 126-131 (2014).

47. Rezaei, J. and Salimi, N. "Economic order quantity and purchasing price for items with imperfect quality when inspection shifts from buyer to supplier", International Journal of Production Economics, 137(1), pp. 11-18 (2012).

48. Taleizadeh, A.A., Kalantari, S.S., and CardenasBarron, L.E. "Determining optimal price, replenishment lot size and number of shipments for an EPQ model with rework and multiple shipments", Journal of Industrial and Management Optimization, 11(4), pp. 1059-1071 (2015).

49. Wu, K.-S., Ouyang, L.-Y., and Ho, C.-H. "Integratedvendor-buyerinventory system with sublot sampling inspection policy and controllable lead time", International Journal of Systems Science, 38, pp. 339-350 (2007).

50. Ha, D. and Kim, S.L. "Implementation of JIT purchasing: an integrated approach", Production Planning and Control, 8(2), pp. 152-157 (1997).

\section{Appendix A}

When $Q, n$, and $n_{M}$ are continuous variables, we prove that Eq. (15) is a convex function.

Taking the first partial derivatives of $E(T C(Q$, $\left.n, n_{M}\right)$ ) with respect to $Q, n$, and $n_{M}$, we have:

$$
\begin{gathered}
\frac{\partial}{\partial Q} E\left(T C\left(Q, n, n_{M}\right)\right)=\frac{1}{2}\left(h_{B}+(n-1) h_{V}\right. \\
\left.+\frac{D h_{V}\left(n E_{b}-\left(n+(n-2) n_{M}\right) E_{a}\right)}{n_{M} P}\right) \\
-\frac{D\left(s_{B}+s_{V}+n_{M} u+n g\right)}{n Q^{2}}, \\
\frac{\partial}{\partial n} E\left(T C\left(Q, n, n_{M}\right)\right)=\frac{Q}{2}\left(h_{V}\right. \\
\left.-\frac{D h_{V}\left(\left(n_{M}+1\right) E_{a}-E_{b}\right)}{n_{M} P}\right) \\
-\frac{D\left(s_{B}+s_{V}+n_{M} u\right)}{n^{2} Q}
\end{gathered}
$$$$
\frac{\partial}{\partial n_{M}} E\left(T C\left(Q, n, n_{M}\right)\right)=\frac{D u}{n Q}-\frac{n Q D\left(E_{b}-E_{a}\right) h_{V}}{2 n_{M}^{2} P} \text { (A.3) }
$$ 


$$
\begin{aligned}
& Q_{C}^{*}=\sqrt{\frac{2 n_{M C}^{*} P D\left(s_{B}+s_{V}+n_{M C}^{*} u+n_{C}^{*} g\right)}{n_{C}^{*} n_{M C}^{*} P h_{B}+h_{V}\left[n_{C}^{*} D\left(E_{b}-E_{a}\right)+n_{M C}^{*}\left(n_{C}^{*}\left(n_{C}^{*}-1\right) P-n_{C}^{*}\left(n_{C}^{*}-2\right) D E_{a}\right)\right]}} . \\
& n_{C}^{*}=\frac{1}{Q_{C}^{*}} \sqrt{\frac{2 n_{M C}^{*} P D\left(s_{B}+s_{V}+n_{M C}^{*} u\right)}{h_{V}\left[D\left(E_{b}-E_{a}\right)+n_{M C}^{*}\left(P-D E_{a}\right)\right]}}, \\
& n_{M C}^{*}=n_{C}^{*} Q_{C}^{*} \sqrt{\frac{h_{V}\left(E_{b}-E_{a}\right)}{2 P u}} .
\end{aligned}
$$

\section{Box A.I}

Setting $Q_{C}^{*}, n_{C}^{*}$, and $n_{M C}^{*}$ as the solutions with which the first partial derivatives in Eqs. (A.1)-(A.3) are equal to zero, respectively, we obtain Eqs. (A.4) to (A.6) as shown in Box A.I. Substituting $n_{C}^{*}$ in Eq. (A.5) into Eq. (A.6), we get:

$$
n_{M C}^{*}=\sqrt{\frac{D\left(E_{b}-E_{a}\right)\left(s_{B}+s_{V}\right)}{\left(P-D E_{a}\right) u}} .
$$

Putting Eq. (A.7) into Eq. (A.5), we have:

$$
n_{C}^{*}=\frac{1}{Q_{C}^{*}} \sqrt{\frac{2 P D\left(s_{B}+s_{V}\right)}{h_{V}\left(P-D E_{a}\right)}} .
$$

Replacing $n_{C}^{*}$ and $n_{M C}^{*}$ in Eq. (A.4) with Eqs. (A.7) and (A.8) gives:

$$
Q_{C}^{*}=\sqrt{\frac{2 P D g}{2 D E_{a} h_{V}+P\left(h_{B}-h_{V}\right)}}
$$

Substituting $Q_{C}^{*}$ in Eq. (A.9) into Eq. (A.8), $n_{C}^{*}$ becomes:

$$
n_{C}^{*}=\sqrt{\frac{\left(2 D E_{a} h_{V}+P\left(h_{B}-h_{V}\right)\right)\left(s_{B}+s_{V}\right)}{\left(P-D E_{a}\right) g h_{V}}} .
$$

We subsequently take the second partial derivatives for $E\left(T C\left(Q, n, n_{M}\right)\right)$ :

$$
\begin{aligned}
& \frac{\partial^{2}}{\partial Q^{2}} E\left(T C\left(Q, n, n_{M}\right)\right) \\
&= \frac{2 D\left(s_{B}+s_{V}+n_{M} u+n g\right)}{n Q^{3}}>0, \\
& \frac{\partial^{2}}{\partial Q \partial n} E\left(T C\left(Q, n, n_{M}\right)\right) \\
&=\frac{\left(D\left(E_{b}-E_{a}-n_{M} E_{a}\right)+n_{M} P\right) h_{V}}{2 n_{M} P}
\end{aligned}
$$

$$
\begin{aligned}
\frac{\partial^{2}}{\partial Q \partial n_{M}} & E\left(T C\left(Q, n, n_{M}\right)\right)=-\frac{n D\left(E_{b}-E_{a}\right) h_{V}}{2 n_{M}^{2} P} \\
& -\frac{D u}{n Q^{2}}
\end{aligned}
$$

$$
\begin{aligned}
\frac{\partial^{2}}{\partial n \partial Q} E\left(T C\left(Q, n, n_{M}\right)\right) \\
=\frac{\left(D\left(E_{b}-E_{a}-n_{M} E_{a}\right)+n_{M} P\right) h_{V}}{2 n_{M} P} \\
+\frac{D\left(s_{B}+s_{V}+n_{M} u\right)}{n^{2} Q^{2}},
\end{aligned}
$$

$$
\frac{\partial^{2}}{\partial n^{2}} E\left(T C\left(Q, n, n_{M}\right)\right)=\frac{2 D\left(s_{B}+s_{V}+n_{M} u\right)}{n^{3} Q}>0
$$

$$
\begin{aligned}
\frac{\partial^{2}}{\partial n \partial n_{M}} & E\left(T C\left(Q, n, n_{M}\right)\right)=-\frac{Q D\left(E_{b}-E_{a}\right) h_{V}}{2 n_{M}^{2} P} \\
& -\frac{D u}{n^{2} Q}
\end{aligned}
$$

$$
\begin{aligned}
\frac{\partial^{2}}{\partial n_{M} \partial Q} & E\left(T C\left(Q, n, n_{M}\right)\right)=-\frac{n D\left(E_{b}-E_{a}\right) h_{V}}{2 n_{M}^{2} P} \\
& -\frac{D u}{n Q^{2}}
\end{aligned}
$$

$$
\begin{aligned}
\frac{\partial^{2}}{\partial n_{M} \partial n} & E\left(T C\left(Q, n, n_{M}\right)\right)=-\frac{Q D\left(E_{b}-E_{a}\right) h_{V}}{2 n_{M}^{2} P} \\
& -\frac{D u}{n^{2} Q}
\end{aligned}
$$




$$
\frac{\partial^{2}}{\partial n_{M}^{2}} E\left(T C\left(Q, n, n_{M}\right)\right)=\frac{n Q D\left(E_{b}-E_{a}\right) h_{V}}{n_{M}^{3} P}>0 .
$$

If $Q_{C}^{*}, n_{C}^{*}$, and $n_{M C}^{*}$ are the optimal solutions of $E\left(T C\left(Q, n, n_{M}\right)\right)$, the following conditions are satisfied:

$$
\begin{aligned}
& \left|H_{1}\right|=h_{11}>0, \quad\left|H_{2}\right|=h_{11} h_{22}-h_{12} h_{21}>0, \\
& \left|H_{3}\right|=\left|\begin{array}{lll}
h_{11} & h_{12} & h_{13} \\
h_{21} & h_{22} & h_{23} \\
h_{31} & h_{32} & h_{33}
\end{array}\right|>0,
\end{aligned}
$$

where $h_{i j}(i, j=1,2,3)$ are the second partial derivatives, i.e. $h_{11}=\frac{\partial^{2}}{\partial Q^{2}} E\left(T C\left(Q, n, n_{M}\right)\right)$, $h_{12}=\partial^{2} / \partial Q \partial n E\left(T C\left(Q, n, n_{M}\right)\right)$ and $h_{13}=\partial^{2} /$ $\partial Q \partial n_{M} E\left(T C\left(Q, n, n_{M}\right)\right)$. From Eq. (A.11), it is obvious that $\left|H_{1}\right|=h_{11}>0$.

To further simplify expressions, let:

$$
\begin{aligned}
& a_{1}=2 D E_{a} h_{V}+P\left(h_{B}-h_{V}\right)>0, \\
& a_{2}=s_{B}+s_{V}>0, \\
& a_{3}=P-D E_{a}>0, \\
& a_{4}=E_{b}-E_{a} \geq 0 .
\end{aligned}
$$

Because $P>E(1 /(1-\beta)) D=E_{a} D$ (see the assumptions in Section 2) and $E_{b}=E\left(1 /(1-\beta)^{2}\right) \geq$ $E(1 /(1-\beta))=E_{a}$, it implies $a_{3}>0$ and $a_{4} \geq 0$. To prove $\left|H_{2}\right|=h_{11} h_{22}-h_{12} h_{21}>0$ on $Q_{C}^{*}, n_{C}^{*}$, and $n_{M C}^{*}$, we rewrite the related equations by using $a_{i}$ shown in Eqs. (A.21)-(A.24). We have:

$$
\begin{aligned}
Q_{C}^{*}= & \sqrt{\frac{2 P D g}{a_{1}}}, \\
n_{C}^{*}= & \sqrt{\frac{a_{1} a_{2}}{a_{3} g h_{V}}}, \\
n_{M C}^{*}= & \sqrt{\frac{D a_{4} a_{2}}{a_{3} u}}, \\
h_{11}= & \frac{\partial^{2}}{\partial Q^{2}} E\left(T C\left(Q, n, n_{M}\right)\right) \\
= & \frac{2 D\left(a_{2}+n_{M} u+n g\right)}{n Q^{3}}>0, \\
h_{12}= & \frac{\partial^{2}}{\partial Q \partial n} E\left(T C\left(Q, n, n_{M}\right)\right) \\
= & \frac{\left(D\left(a_{4}-n_{M} E_{a}\right)+n_{M} P\right) h_{V}}{2 n_{M} P} \\
& +\frac{D\left(a_{2}+n_{M} u\right)}{n^{2} Q^{2}},
\end{aligned}
$$

$$
\begin{aligned}
h_{21}= & \frac{\partial^{2}}{\partial n \partial Q} E\left(T C\left(Q, n, n_{M}\right)\right) \\
= & \frac{\left(D\left(a_{4}-n_{M} E_{a}\right)+n_{M} P\right) h_{V}}{2 n_{M} P} \\
& +\frac{D\left(a_{2}+n_{M} u\right)}{n^{2} Q^{2}}, \\
h_{22}= & \frac{\partial^{2}}{\partial n^{2}} E\left(T C\left(Q, n, n_{M}\right)\right)=\frac{2 D\left(a_{2}+n_{M} u\right)}{n^{3} Q} .
\end{aligned}
$$

We apply Eqs. (A.28)-(A.31) to calculate $\left|H_{2}\right|=$ $h_{11} h_{22}-h_{12} h_{21}$.

Then, substituting Eqs. (A.25)-(A.27) for $Q, n$, and $n_{M}$ in $\left|H_{2}\right|$, we take $\left|H_{2}\right|>0$. Applying mathematical software for simplification of equations, we can obtain $\left|H_{3}\right|>0$.

\section{Appendix B}

Taking the second partial derivatives of $E^{2}(T C(n$, $\left.n_{M}\right)$ ) with respect to $n$ and $n_{M}$, we have:

$$
\begin{aligned}
& \frac{\partial^{2}}{\partial n^{2}} E^{2}\left(T C\left(n, n_{M}\right)\right) \\
& \quad=\frac{4 D\left(2 D E_{a} h_{V}+P\left(h_{B}-h_{V}\right)\right)\left(s_{B}+s_{V}+n_{M} u\right)}{n^{3} P},
\end{aligned}
$$

$\frac{\partial^{2}}{\partial n_{M}^{2}} E^{2}\left(T C\left(n, n_{M}\right)\right)$

$$
=\frac{4 D^{2} h_{V}\left(E_{b}-E_{a}\right)\left(s_{B}+s_{V}+n g\right)}{n_{M}^{3} P},
$$

$$
\begin{gathered}
\frac{\partial^{2}}{\partial n \partial n_{M}} E^{2}\left(T C\left(n, n_{M}\right)\right)=-\left(\frac{2 D^{2} g h_{V}\left(E_{b}-E_{a}\right)}{n_{M}^{2} P}\right. \\
\left.+\frac{2 D u\left(2 D E_{a} h_{V}+P\left(h_{B}-h_{V}\right)\right)}{n^{2} P}\right)
\end{gathered}
$$

Letting:

$$
\begin{aligned}
|H| & =\frac{\partial^{2}}{\partial n^{2}} E\left(T C\left(n, n_{M}\right)\right) \cdot \frac{\partial^{2}}{\partial n_{M}^{2}} E\left(T C\left(n, n_{M}\right)\right) \\
& -\left(\frac{\partial^{2}}{\partial n \partial n_{M}} E\left(T C\left(n, n_{M}\right)\right)\right)^{2}
\end{aligned}
$$

we get:

$$
\begin{aligned}
& |H|= \\
& \quad \frac{4 D\left(2 D E_{a} h_{V}+P\left(h_{B}-h_{V}\right)\right)\left(s_{B}+s_{V}+n_{M} u\right)}{n^{3} P}
\end{aligned}
$$




$$
\begin{aligned}
& \frac{\partial^{2}}{\partial n^{2}} E^{2}\left(T C\left(n, n_{M}\right)\right)=\frac{4 D a_{1}\left(a_{2}+n_{M} u\right)}{n^{3} P}, \\
& \frac{\partial^{2}}{\partial n \partial n_{M}} E^{2}\left(T C\left(n, n_{M}\right)\right)=-\left(\frac{2 D^{2} g h_{V} a_{4}}{n_{M}^{2} P}+\frac{2 D u a_{1}}{n^{2} P}\right), \\
& \frac{\partial^{2}}{\partial n_{M}^{2}} E^{2}\left(T C\left(n, n_{M}\right)\right)=\frac{4 D^{2} h_{V} a_{4}\left(a_{2}+n g\right)}{n_{M}^{3} P}, \\
& |H|=\frac{4 D^{2}\left(4 n_{M} n D h_{V} a_{1} a_{4}\left(a_{2}+n_{M} u\right)\left(a_{2}+n g\right)-\left(n_{M}^{2} u a_{1}+n^{2} D g h_{V} a_{4}\right)^{2}\right)}{n_{M}^{4} n^{4} P^{2}} .
\end{aligned}
$$

\section{Box B.I}

$$
\left.|H|\right|_{n=n \#, n_{M}=n_{M}^{\#}}=\frac{16 D g h_{V}^{2} u^{2} a_{3}^{2}\left(D a_{4} \sqrt{a_{1} a_{2} a_{3} g h_{V}}+a_{3} \sqrt{\frac{D a_{2} a_{4}}{u a_{3}}}\left(g a_{1}+\sqrt{a_{1} a_{2} a_{3} g h_{V}}\right)\right)}{a_{1} a_{2}^{2} a_{4} P^{2}}>0 .
$$

Box B.II

$$
\begin{aligned}
& \times \frac{4 D^{2} h_{V}\left(E_{b}-E_{a}\right)\left(s_{B}+s_{V}+n g\right)}{n_{M}^{3} P} \\
& -\left(\frac{2 D^{2} g h_{V}\left(E_{b}-E_{a}\right)}{n_{M}^{2} P}\right. \\
& \left.+\frac{2 D u\left(2 D E_{a} h_{V}+P\left(h_{B}-h_{V}\right)\right)}{n^{2} P}\right)^{2} .
\end{aligned}
$$

Substituting $a_{i}$ in Eqs. (A.21)-(A.24) into the above equations, we have Eqs. (B.5) to (B.8) as shown in Box B.I.

Subsequently, we can rewrite $n_{M}^{\#}$ in Eq. (25) and $n^{\#}$ in Eq. (26) as:

$$
\begin{aligned}
& n_{M}^{\#}=\sqrt{\frac{D a_{2} a_{4}}{u a_{3}}}, \\
& n^{\#}=\sqrt{\frac{a_{1} a_{2}}{g h_{V} a_{3}}} .
\end{aligned}
$$

Substituting Eqs. (B.9) and (B.10) for $n_{M}$ and $n$ in Eq. (B.8), we obtain Eq. (B.11) as shown in Box B.II. Therefore, $n_{M}^{\#}$ in Eq. (25) and $n^{\#}$ in Eq. (26) are the optimal solutions that minimize $E^{2}\left(T C\left(n, n_{M}\right)\right)$.

\section{Biographies}

Yung-Lung Cheng received his $\mathrm{PhD}$ degree from the Department of Industrial and Systems Engineering at Chung Yuan Christian University in Taiwan. His works have been published in Renewable and Sustainable Energy Reviews, Applied Mathematics and Computation, etc. His research interests include production/inventory control and supply chain management.

Wan-Tsu Wang received his $\mathrm{PhD}$ degree from the Department of Industrial and Systems Engineering at Chung Yuan Christian University in Taiwan. His works have been published in Decision Support Systems, OMEGA, European Journal of Operational Research, etc. His research interests include production/inventory control and supply chain management.

Chun-Chin Wei received his $\mathrm{PhD}$ degree from the Department of Industrial Engineering and Engineering Management at Tsing Hua University in Taiwan. His works have been published in various international journals. His research interests include inventory control, decision-making, and supply chain management.

Kuo-Liang Lee is an Assistant Professor in the Department of Industrial Engineering and Management at Ching Yun University in Taiwan. He received his doctoral degree in Industrial Engineering and Manufacturing from Cleveland State University in USA. His research interests include quality management, service quality, and Six Sigma management. He is also a 
Six Sigma consultant and an ISO 9001 Lead Auditor. There are many firms that have benefited from his help. Dr. Lee is an Associate Professor and the Chairman of the Department of Industrial Management at Chien Hsin University of Science and Technology in Taiwan. He received his $\mathrm{PhD}$ degree in Industrial Engineering and Manufacturing from Cleveland State University in USA. His research interests include quality management, service quality, and Six Sigma management and Lean Six Sigma. He is also a Six Sigma consultant and an ISO 9001:2015 Lead Auditor. There are many firms that have benefited from his help. 